\title{
Experimental evidence of the simultaneous occurrence of VLF chorus on the ground in the global azimuthal scale - from pre-midnight to the late morning
}

\author{
J. Manninen ${ }^{1}$, N. G. Kleimenova ${ }^{2}$, O. V. Kozyreva ${ }^{2}$, M. Parrot ${ }^{3}$, T. Raita ${ }^{1}$, and T. Turunen ${ }^{1}$ \\ ${ }^{1}$ Sodankylä Geophysical Observatory, Finland \\ ${ }^{2}$ Institute of the Earth Physics RAS, Moscow, Russia \\ ${ }^{3}$ LPC2E/CNRS, Orléans, France \\ Correspondence to: J. Manninen (jyrki.manninen@sgo.fi)
}

Received: 25 January 2012 - Revised: 26 March 2012 - Accepted: 26 March 2012 - Published: 24 April 2012

\begin{abstract}
Night-time VLF (very low frequency) chorus bursts lasting about one hour have been recorded at Finnish temporal station Kannuslehto (CGM: $64.2^{\circ} ; 107.9^{\circ}, L=5.3$ ) during two VLF campaigns (on 25 February-4 March 2008 and 27 March-17 April 2011). The chorus bursts were associated with substorm development. They were accompanied by riometer absorption enhancements, which occurred simultaneously within as large longitude areas as from pre-midnight (Sodankylä, 22:00 MLT) to the late morning (Tixie, $\sim 03: 00$ MLT and Gakona, 08:00 MLT) longitudes. It was found that the pre-midnight chorus observed on the ground occurred simultaneously with VLF chorus emissions recorded in the late morning on the low-altitude DEMETER satellite crossing the similar geomagnetic latitudes on the opposite local time sector. For the first time some evidence of simultaneous chorus burst generation in the global longitudinal scale was found (from pre-midnight to the late morning) by using direct comparison with satellite data as well as using non-direct indicator-azimuthally extended riometer absorption enhancements.
\end{abstract}

Keywords. Ionosphere (Particle precipitation; Waveparticle interactions) - Magnetospheric physics (Plasma waves and instabilities)

\section{Introduction}

The whistler mode VLF (very low frequency) chorus is one of the most spectacular kinds of the magnetospheric plasma waves. Chorus activity is typical for the early morning hours, and therefore these emissions are called "dawn chorus". The properties and nature of the chorus have been discussed in a large number of experimental and theoretical papers. Chorus emissions such as whistler-mode wave packets propagate roughly along magnetic field lines from a localized source in the vicinity of the magnetic equator in the low-density region outside the plasmapause. The chorus is believed to be generated through electron cyclotron instability. The chorus generation can be attributed to the nonlinear theory of backward wave oscillator (BWO) model, which assumes a step-like velocity distribution of energetic electrons (e.g. Trakhtengerts, 1995; Kozelov et al., 2008). These VLF emissions can be a driver of energetic electron precipitation, which is typically accompanied by the chorus (e.g. Tsurutani and Smith, 1974; Anderson and Maeda, 1977; Bortnik and Thorne, 2007; Gołkowski and Inan, 2008; Manninen et al., 2010).

The VLF data observed by Cluster (e.g. Santolik and Gurnett, 2003) and THEMIS (e.g. Agapitov et al., 2010) spacecrafts showed that the dimension of the source region of an individual chorus wave packet is $\sim 3000-5000 \mathrm{~km}$ along the magnetic field lines and a few tens of kilometres in the perpendicular plane. The statistical distribution (vs. MLT, Lvalue, Kp) of VLF chorus, recorded on different spacecrafts, showed that chorus emissions are usually observed between 23:00 and 13:00 MLT, but typically in the dawn sector (e.g. Tsurutani and Smith, 1974).

Recently, using high-resolution VLF data from THEMIS, the global distribution of chorus in the magnetosphere was statistically studied by Li et al. $(2009,2011)$ separately for lower-band chorus ( $f \sim 0.1-0.5$ fce) and upper-band chorus 


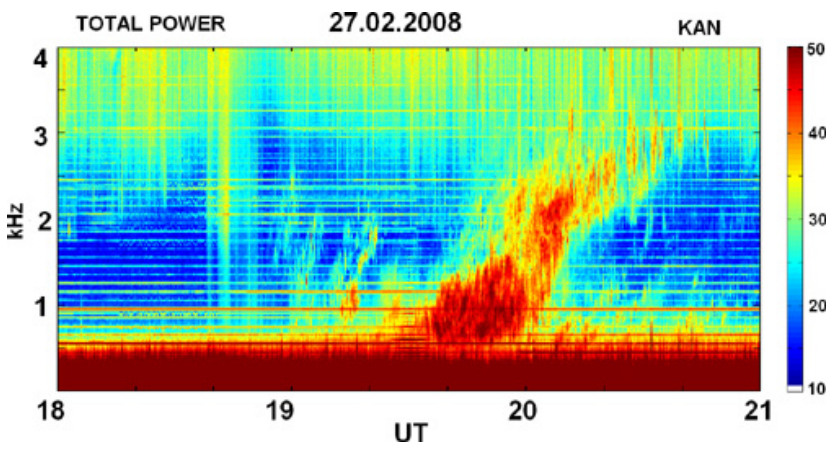

Fig. 1. Spectrogram of the chorus event on 27 February 2008.

( $f \sim 0.5-0.8$ fce), where fce is the equatorial electron cyclotron frequency. Only the lower-band chorus is effective detected on the ground. According to Li et al. (2009, 2011) statistical results, the large amplitude lower-band chorus waves are observed from pre-midnight to post-dawn near the magnetic equator with an occurrence rate of up to a few percent. However, statistical study could not estimate the longitudinal extend of the simultaneous occurrence of the individual chorus bursts. Relatively few studies (e.g. Harang, 1968; Kleimenova et al., 1970, 1975, 1977) presented quantitative treatment of multiple ground-based chorus observations, mostly studying the chorus distribution along the meridian. Due to a very limited number of longitude separated VLF stations, the longitudinal extent of the individual simultaneous chorus bursts is still not known.

The aim of this paper is to study the peculiarities of the night-time chorus bursts observed during two Finnish VLF campaigns in 2008 and 2011, their relationship with precipitated particles (via riometer absorption) and, of particular interest, to estimate the longitudinal extent of the simultaneous occurrence of the chorus bursts.

\section{Observations}

Here we analysed the ground-based VLF data recorded in Northern Finland at Kannuslehto during two VLF campaigns on 25 February-4 March 2008 and 27 March-17 April 2011 $\left(\mathrm{KAN}, \phi=67.74^{\circ} \mathrm{N}, \lambda=26.27^{\circ} \mathrm{E}, \mathrm{CGM} 64.2^{\circ} ; 107.9^{\circ}\right.$, $L=5.3)$. The VLF receiver contains two orthogonal horizontal magnetic components, and the recorded frequency band is $0.2-39 \mathrm{kHz}$.

For the detailed analysis, we selected 4 night-time chorus events. The data were compared to the riometer observations at 3 azimuthally separated auroral stations: Sodankylä (SOD, CGM 63.8 $; 107.6^{\circ}, L=5.2$ ), Tixie (TIX, CGM $65.3^{\circ} ; 196.3^{\circ}, L=5.6$ ), and Gakona (GAK, CGM $\left.63.1^{\circ} ; 267.2^{\circ}, L=4.9\right)$. It is well known that the cyclotron wave-particle interaction results in a decrease of the pitch angle of the resonant electrons and leads to their precipita-

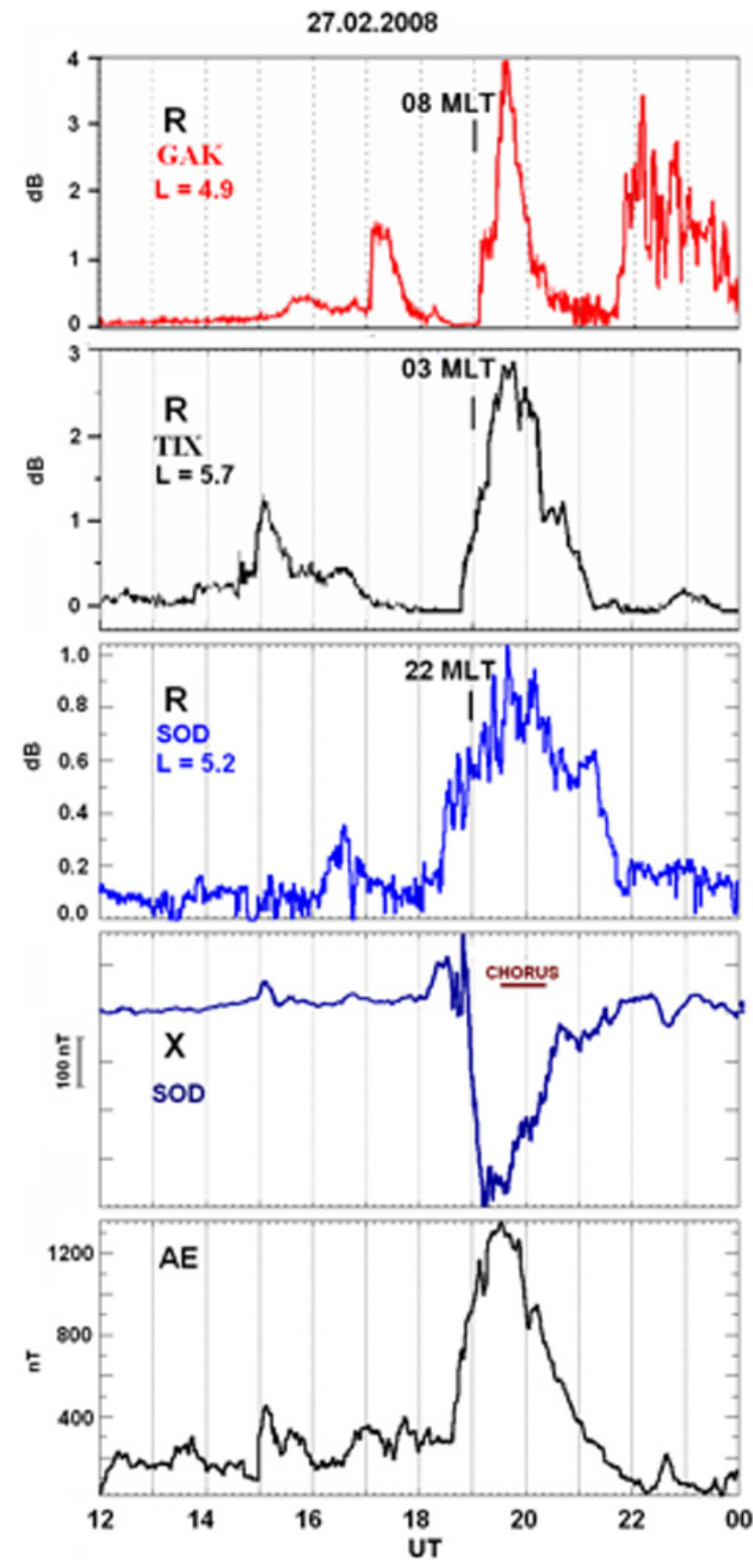

Fig. 2. Riometer data at three stations (GAK, TIX and SOD), Xcomponent at SOD, and the variations of AE-index.

tion. Electron precipitation can be monitored on the ground using a riometer, which indicates the absorption of cosmic radio noise due to charged particle density variations in the ionosphere. 


\subsection{Night chorus events on 27 February 2008 and 1 March 2008}

On 27 February 2008, the chorus burst (Fig. 1) at KAN was observed before the local magnetic midnight $(\sim 22: 00$ 23:00 MLT). These chorus emissions demonstrated the presence of both types of the wave polarization: left-hand and right-hand (not shown here), but mostly the right-hand one. It could be interpreted as the ionospheric exit point location not very far from the ground receiver (Yearby and Smith, 1994), and the signals came from different distances, not only overhead. The multiple exit point case shows chorus waves impinging on the ionosphere over a wide magnetic latitude range, suggesting non-ducted wave propagation above the ionosphere (Gołkowski and Inan, 2008).

Prior to the chorus burst, there was an onset of the strong substorm (AE-index 13:50 nT) (Fig. 2). The substorm onset was accompanied by the breakup of the visible auroras, the burst of the auroral hiss (at $\sim 18: 40$ UT, Fig. 1), the Pi2 and Pi1B geomagnetic pulsations, which are typical for substorm onset, and the enhanced riometer absorption at SOD $(L=5.2)$. This chorus event was accompanied by the riometer absorption increase, observed simultaneously within wide longitude range (Fig. 2): from the late evening (SOD, $\sim 22: 00 \mathrm{MLT}$ ) to the morning (TIX, $\sim 03: 00$ MLT and GAK, $\sim 08: 00$ MLT), demonstrating a very large azimuthal extending from the area of the simultaneous energetic electron precipitation during the discussed above chorus event.

A similar night-time chorus event (Fig. 3) was recorded at KAN near the local magnetic mid-night on 1 March 2008. The chorus burst was accompanied by PilC type noiselike geomagnetic pulsations (bottom panel in Fig. 3), which are typical for dawn hours and usually associated with an electron precipitation (e.g. Troitskaya and Kleimenova, 1972), and enhanced riometer absorption. Auroral hiss ( 20:00 UT) accompanied the substorm onset, which preceded the chorus emissions (Fig. 3). As in the previous event, auroral hiss was characterized by the pure right-hand polarization, and the chorus demonstrated the presence of both kinds of polarizations (not shown here).

It should be noted that during both events, a chorus was also observed at $\sim 05: 00-06: 00$ MLT sector at Yakutsk (S. Samsonov and V. Mullayarov, private communication). But we cannot directly compare the duration of the chorus and its exact onset and end at KAN and Yakutsk due to the significant difference of the VLF receivers and their sensitivities at these stations.

\subsection{Comparison of the VLF data between ground and DEMETER satellite observations}

In order to study the longitudinal extension of the chorus, we compared the night-time chorus at KAN with the simultaneous VLF recordings on the low-altitude $(\sim 700 \mathrm{~km})$ satellite DEMETER crossing similar geomagnetic latitudes in the op-

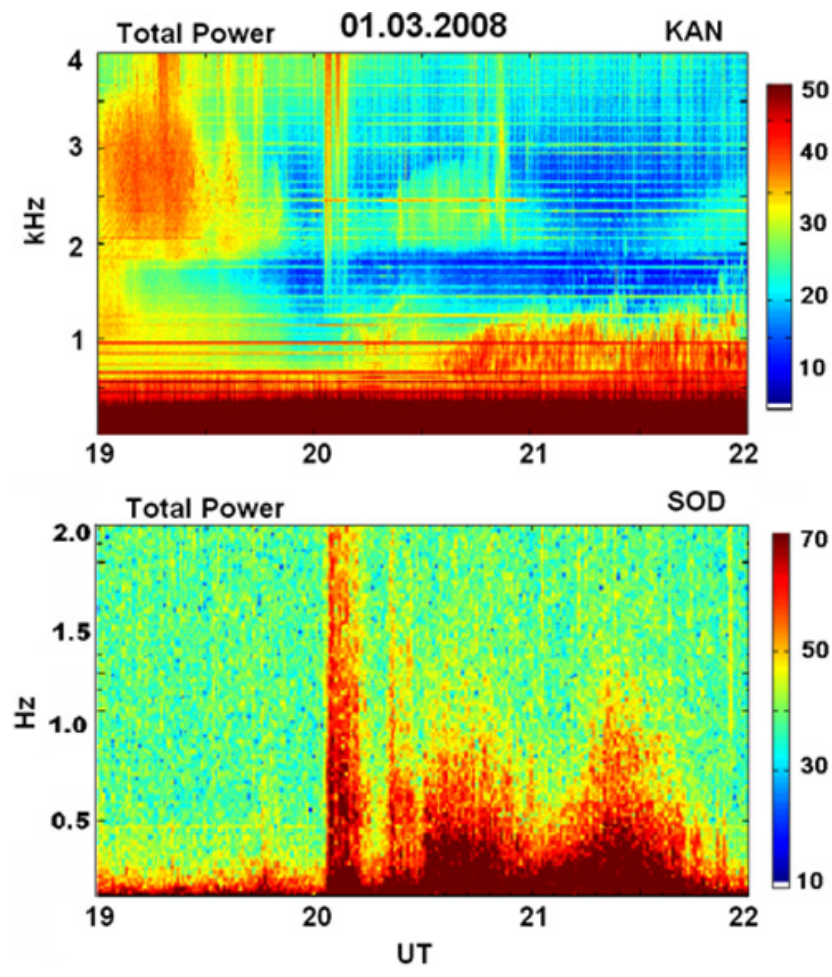

Fig. 3. Spectrograms of the event on 1 March 2008 (SOD): upper panel - chorus, bottom panel - PiB and Pi1C geomagnetic pulsations.

posite local time sector, i.e. in the late morning, during a few minutes approximately every two hours. Unfortunately, on 27 February 2008, there were no DEMETER orbits crossing suitable L-shells at the time of the chorus observations at KAN. However, a few minutes after the end of the chorus burst at KAN, the DEMETER satellite crossed the $L \sim 4-6$ area at 21.04-21.06 UT and registered there the chorus emissions (Fig. 4a). Clearly, in the late morning side, chorus could last slightly longer than in the night side. In the previous DEMETER orbit at 19.13-19.15 UT (at $L \sim 4-6$ ), there was no chorus.

Fortunately, during the chorus event (Fig. 3) on 1 March 2008, the DEMETER satellite crossed the $L \sim 3-$ 7 area in both hemispheres (Fig. 4b). At 20:58-21:02 UT, the DEMETER satellite was in the late morning sector ( 10:00 MLT) in the Northern Hemisphere and measured the chorus emissions at the wide latitude area (at least, from $L \sim 3$ to $L \sim 7$ ). About a half an hour later, at 21:3121:33 UT, the DEMETER crossed similar L-shells in the Southern Hemisphere at $\sim 09: 30$ MLT and recorded the chorus emissions there as well.

Thus, in both events, the night-time chorus at KAN was accompanied by the post-dawn chorus measured on DEMETER. The strong riometer absorption was also observed during this time by the $30 \mathrm{MHz}$ riometer at GAK, located near the meridian of the considered position of the DEMETER 
(a) DEMETER

Date: 2008/02/27 Orbit: $19542 \_0$

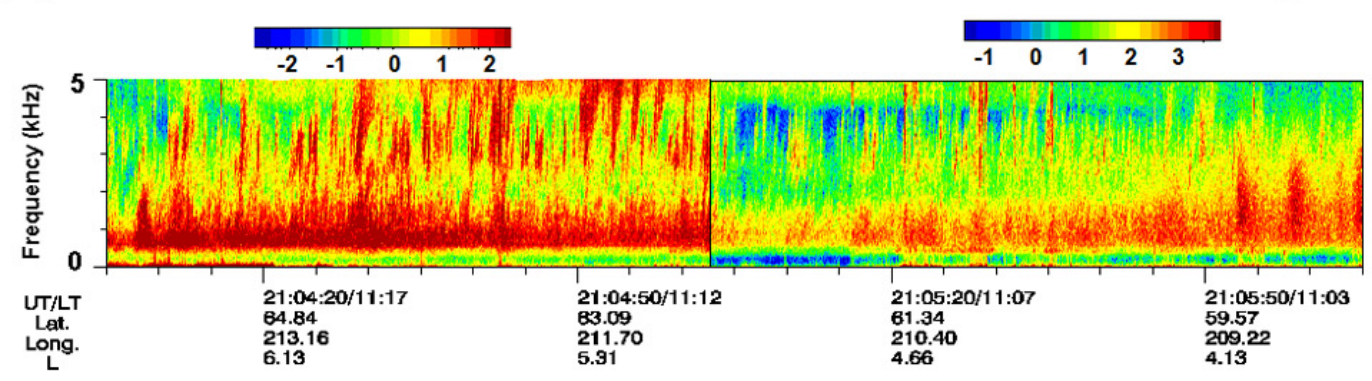

(b)

NORTHERN HEMISPHERE
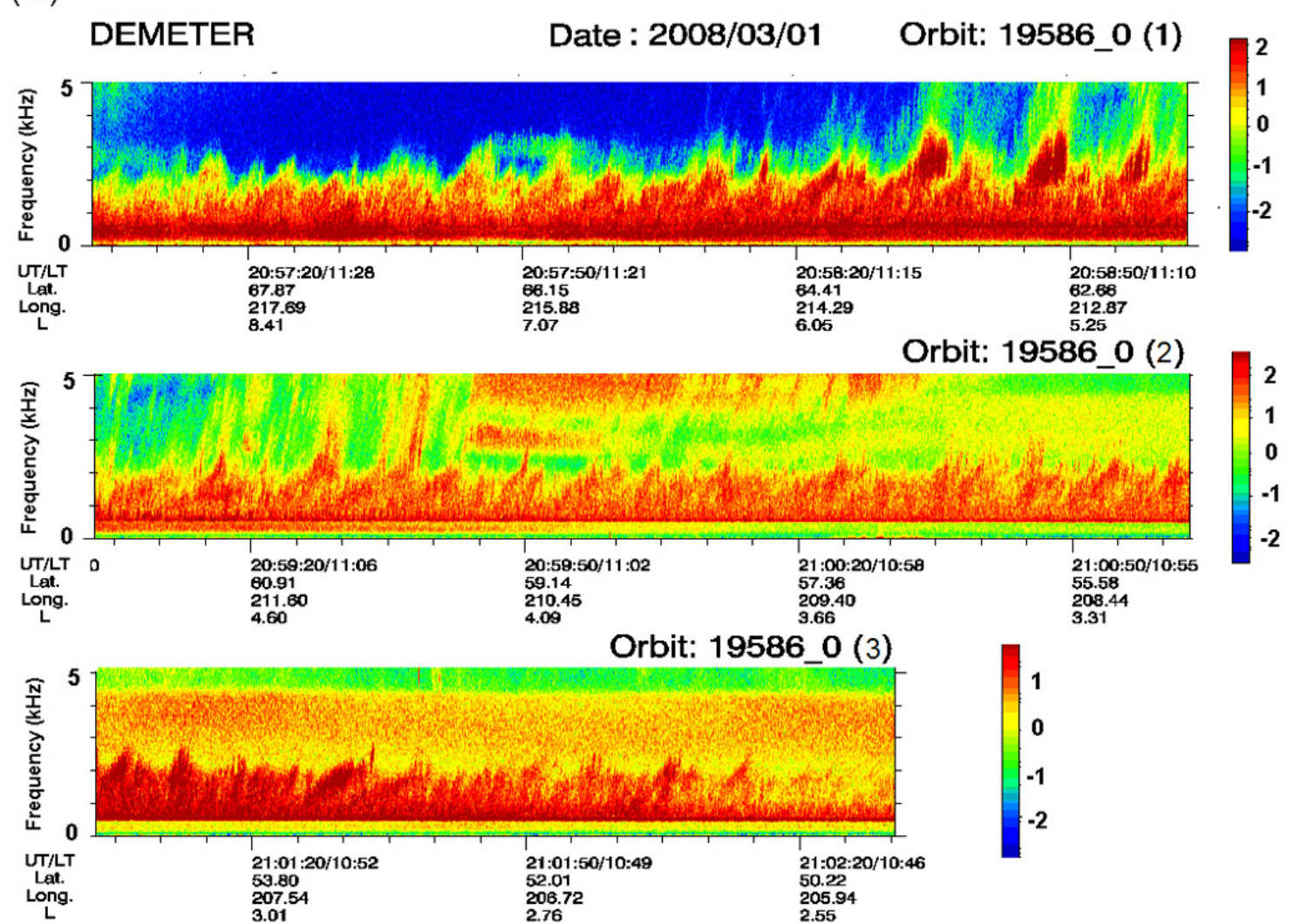

SOUTHERN HEMISPHERE

DEMETER

Date: 2008/03/01

Orbit: 19586_0 (5)

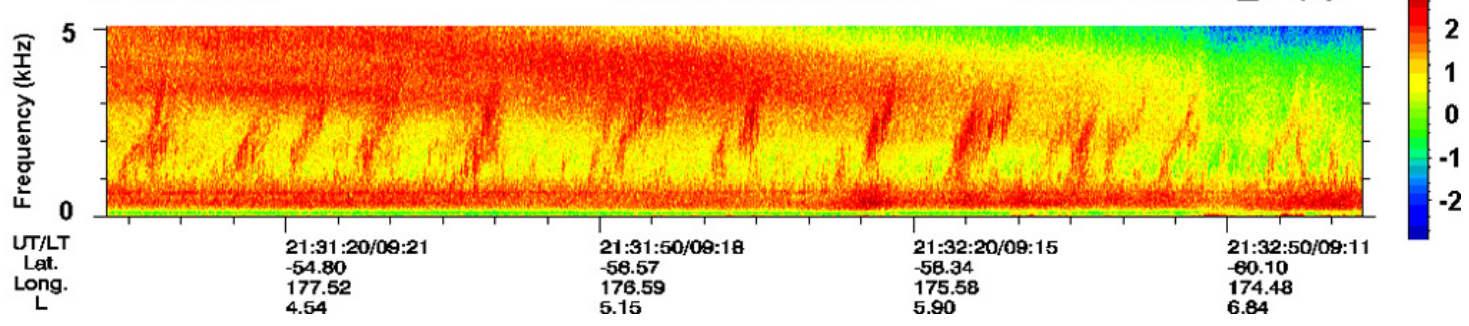

Fig. 4. DEMETER VLF data (a) on 27 February 2008 as the united data from two parts of the orbit with the different scales and (b) on 1 March 2008. The latitudes and longitudes are given in the geographic coordinates. 

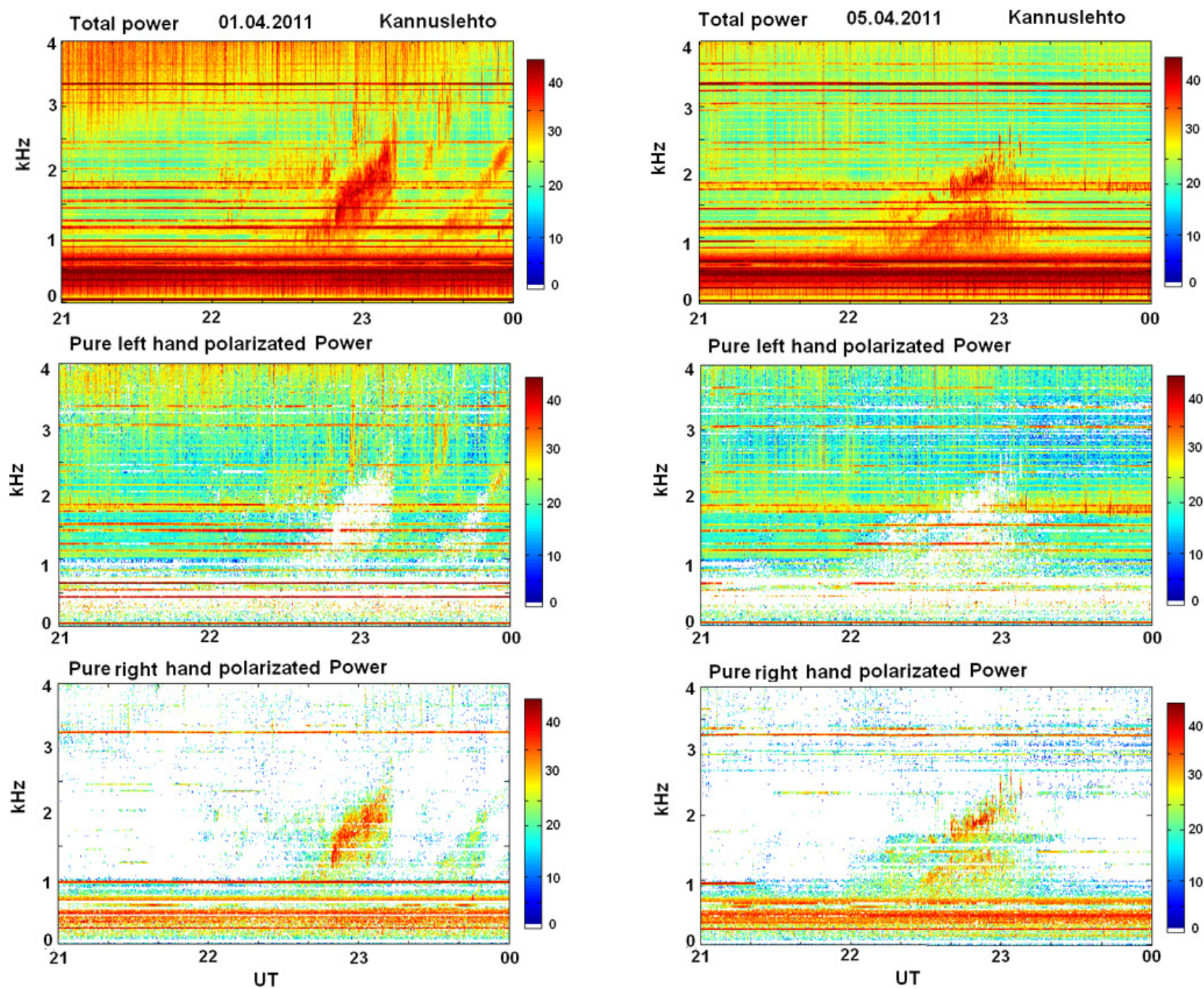

Fig. 5. Spectrograms of the chorus events on 1 April (left) and 5 April (right) 2011: total power, left-hand and right-hand polarized wave power.

orbits ( 10:00 MLT). Thus, there were energetic particle precipitations at all sites where the chorus was observed. This suggests that the large longitude area of the simultaneous chorus occurrence is the result of the chorus generation instead of the behaviour of the signal propagation.

It should be noted that the high frequency cut-off of chorus observed simultaneously in the night and late morning sectors could be different. One reason is that the night and morning chorus were generated at different L-shells because the injected and drifting electrons from night-side to dayside were moving towards the Earth (e.g. Shukhtina and Sergeev, 1991). Moreover, most of the night-time chorus can be distinguished from morning chorus by sharp increasing frequency of the emission burst envelope (e.g. Fig. 1). This may be attributed to the combined effects of the dispersion of electron energy due to gradient and curvature drifts, and the modification of resonance conditions and variation of the half-gyrofrequency cut-off (Collier and Hughes, 2004).

\subsection{Night-time chorus bursts observed on 1 and 5 April 2011}

The new Finnish VLF campaign was carried out between 28 March and 17 April 2011 at KAN. The night-time chorus bursts were observed on 1 and 5 April 2011 (Fig. 5), showing mostly pure right-hand polarization interpreted as the location of the exit point overhead the receiver. These chorus bursts came from overhead ionosphere instead of travelling in the Earth-ionosphere waveguide. As in the previous events, the bursts of night-time chorus were accompanied 


\subsubsection{1}

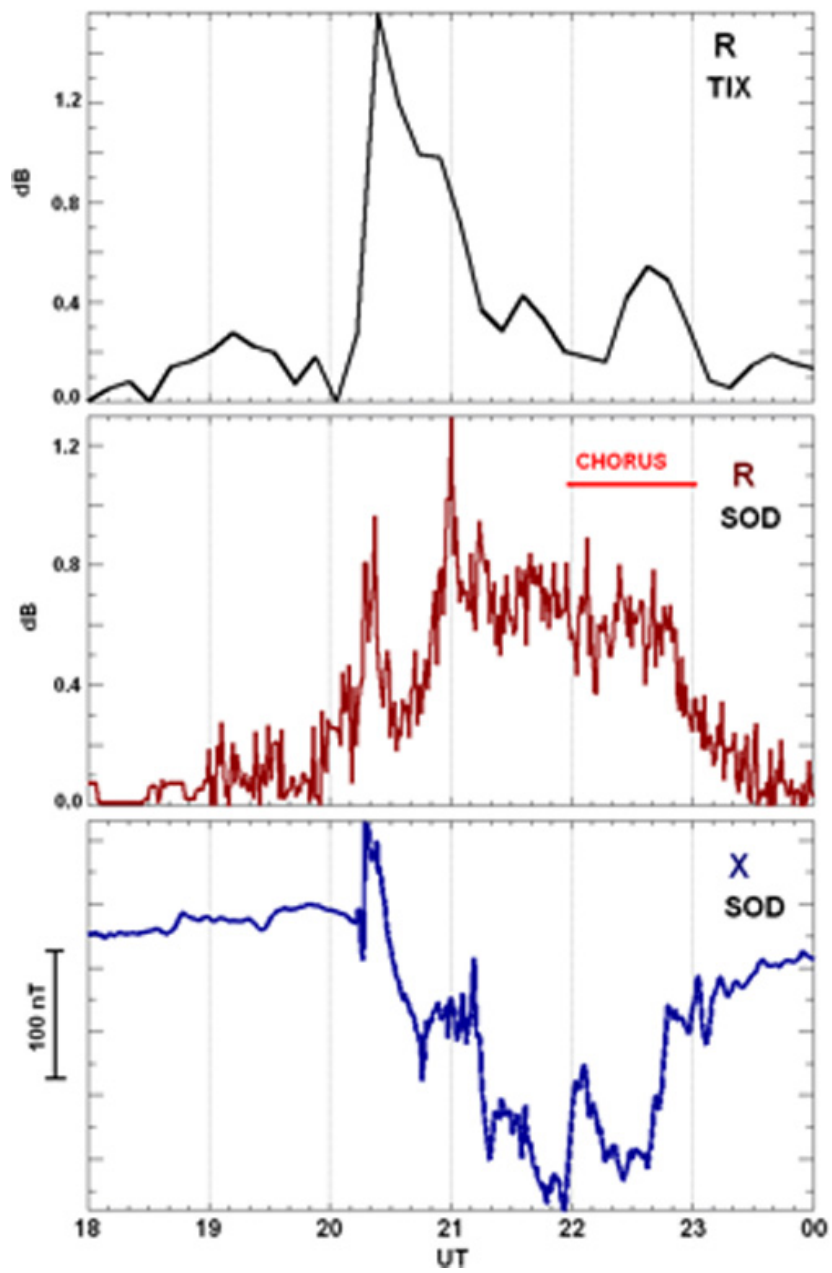

Fig. 6. Riometer data at TIX and SOD, and X-component at SOD (bottom panel) on 5 April 2011.

by riometer absorption enhancements, both near local night (SOD) and in the morning (TIX), as it is shown in Fig. 6.

\section{Discussion}

It is well established that classical morning chorus, associated with substorm, is related to the energetic electrons, injected during substorm in the night sector and drifting toward the morning side. The relation of chorus morphology to the storm-time injection and eastward azimuthal drift of energetic electrons has been reported by many authors (e.g. Anderson and Maeda, 1977; Collier and Hughes, 2004; Smith et al., 2004; Bortnik and Thorne, 2007). They all came to the conclusion that the electron pitch-angle diffusion by interaction with the whistler-mode waves (chorus) is the basic mechanism of formation of the pitch-angle distribution of energetic electrons leading to their precipitation. Moreover,
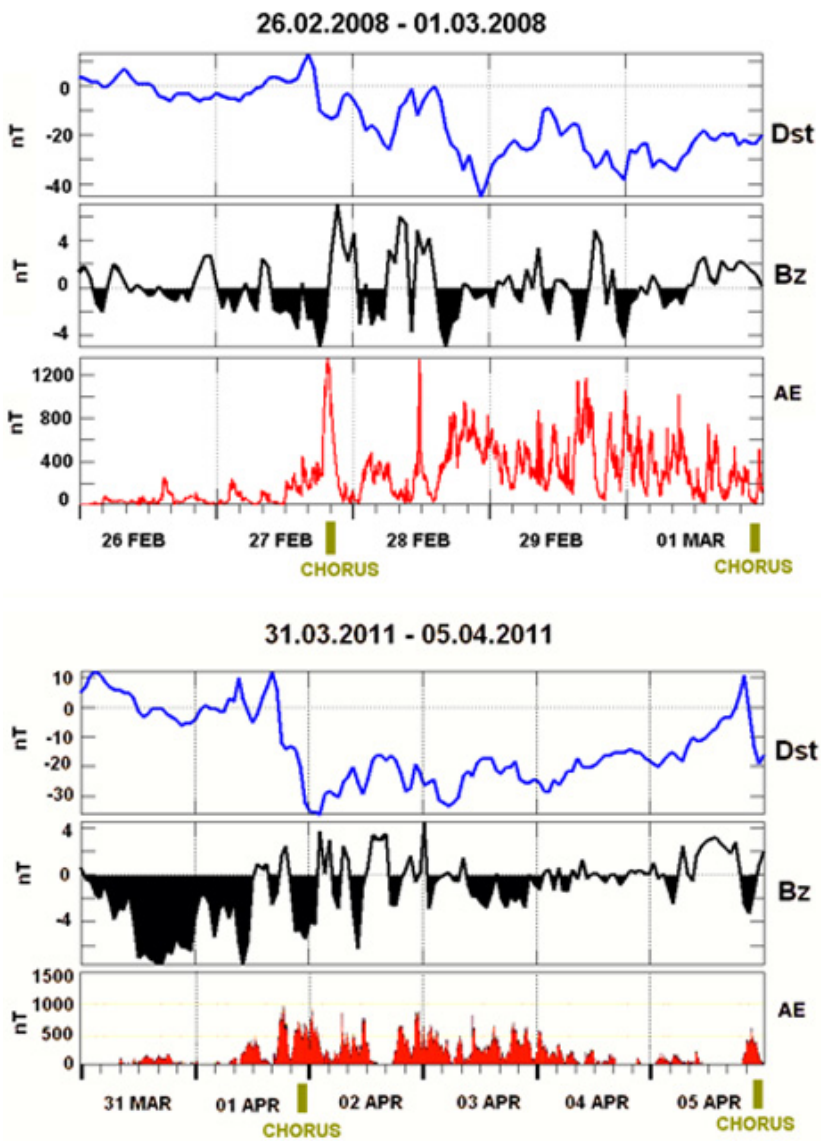

Fig. 7. Geomagnetic conditions in the intervals of night chorus bursts in 2008 and 2011; from top to bottom: variations of Dst-index, IMF $B_{\mathrm{Z}}$ component and AE-index for 26 February1 March 2008 (upper panel) and 31 March-5 April 2011 (bottom panel).

Bortnik et al. (2008) demonstrated that low amplitude chorus exhibit linear electron scattering, whereas large amplitude wave can result in monotonic decreases in pitch angle and energy, causing a large-scale particle loss.

The chorus events under consideration were observed during the small magnetic storms after prolonged intervals (more than $15 \mathrm{~h}$ ) with the negative IMF $B_{\mathrm{z}}$ (Fig. 7). These created conditions where trapped energetic electrons, filling the magnetosphere, provided the favourable conditions for VLF wave generation through the electron cyclotron instability and respective energetic particle precipitations, recorded on the ground as an increase of the riometer absorption. The strong correlation between chorus and precipitating energetic electrons was formerly shown by many satellite measurements, e.g. Injun-3 (Oliven and Gurnett, 1968), OGO-6 (Holzer et al., 1974) and SAMPEX (Lorentzen et al., 2001). Every burst of precipitating electrons was accompanied by chorus emissions. 
During all considered chorus events there were the riometer absorption enhancements, which were caused by energetic electron precipitation. These enhancements have been observed simultaneously in the huge longitudinal area - from the pre-midnight to the late morning sector - without any significant delay. Because of reasons mentioned in Sect. 2.2, the simultaneous occurrence of the azimuthally extended riometer absorption can be the non-direct evidence of the chorus generation in the global longitude scale. The enhanced magnetic activity and prolonged substorm activity prior to the considered chorus events offer a necessary condition for their generation.

\section{Conclusion}

For the first time, based on the ground observations, it was found that the VLF chorus bursts were recorded simultaneously in a very large longitude area - from the pre-midnight to the late morning - during a substorm after prolonged intervals with the slightly negative IMF $B_{\mathrm{Z}}$ values. These chorus bursts were accompanied by enhancements of riometer absorption in the wide azimuthally extended area. This may be non-direct evidence of the simultaneously exiting electroncyclotron instability in the global longitude scale, and suggests that the observations of chorus were extended longitudinally due to the simultaneous generation at different longitudes instead of behaviour of the signal propagation. The mostly right-hand polarisation of the considered chorus at KAN demonstrated that these waves arrived from the ionosphere exit located approximately overhead, not long travelling in the wave-guide.

This finding of the simultaneous chorus bursts occurrence in the global longitude scale is important for understanding the loss and acceleration mechanisms of energetic electrons of the radiation belt dynamics in which chorus waves are believed to play a major role.

Acknowledgements. The authors thank S. N. Samsonov and V. A. Mullayarov for Tixie riometer and VLF data, respectively. This work was partly supported by Russian Foundation for Basic Research (project No. 10-05-00247). N.K. and O.K. acknowledge Sodankyla Geophysical Observatory for the financial support during their visit.

Topical Editor R. Nakamura thanks F. Nemec for his help in evaluating this paper.

\section{References}

Agapitov, O., Krasnoselskikh, V., Zaliznyak, Yu., Angelopoulos, V., Le Contel, O., and Rolland, G.: Chorus source region localization in the Earth's outer magnetosphere using THEMIS measurements, Ann. Geophys., 28, 1377-1386, doi:10.5194/angeo28-1377-2010, 2010.

Anderson, R. R. and Maeda, K.: VLF emissions associated with enhanced magnetospheric electrons, J. Geophys. Res., 82, 135146, 1977.
Bortnik, J. and Thorne, R. M.: The dual role of ELF/VLF chorus waves in the acceleration and precipitation of radiation belt electrons, J. Atmos. Sol. Terr. Phys., 69, 377-386, 2007.

Bortnik, J., Thorne, R. M., and Inan, U. S.: Nonlinear interaction of energetic electrons with large amplitude chorus, Geophys. Res. Lett., 35, L21102, doi:10.1029/2008GL035500, 2008.

Collier, A. B. and Hughes, A. R. W.: Modelling substorm chorus events in terms of dispersive azimuthal drift, Ann. Geophys., 22, 4311-4327, doi:10.5194/angeo-22-4311-2004, 2004.

Gołkowski, M. and Inan, U. S.: Multistation observations of ELF/VLF whistler mode chorus, J. Geophys. Res., 113, A08210, doi:10.1029/2007JA012977, 2008.

Harang, L.: VLF-emissions observed at stations close to the auroral zone and at stations on lower latitudes, J. Atmos. Terr. Phys., 30, 1143-1160, 1968.

Holzer, R. E., Farley, T. A., and Burton, R. K.: A correlated study of ELF-waves and electron precipitation on OGO-6, J. Geophys. Res., 79, 1007-1013, 1974.

Kleimenova, N. G., Raspopov, O. M., Vigneron, J., and Nguen Kim Thoa: Longitude drift of VLF chorus and their relationship with magnetic disturbances at the night-side of the Earth, Geomag. Aeron., 8, 854-859, 1970.

Kleimenova, N. G., Holtet, J., and Egeland, A.: Latitude drift of polar chorus, Bulletin IAGA, 36, 113, 1975.

Kleimenova, N. G., Novikov, Yu. P., Smirnova, N. A., Titova, E. E., and Holtet, J.: VLF-emission along the magnetic meridian, Ionosphernie Issledov., 21, 64-68, 1977 (in Russian).

Kozelov, B. V., Demekhov, A. G., Titova, E. E., Trakhtengerts, V. Y., Santolik, O., Macusova, E., Gurnett, D. A., and Pickett, J. S.: Variations in the chorus source location deduced from fluctuations of the ambient magnetic field: Comparison of Cluster data and the backward wave oscillator model, J. Geophys. Res., 113, A06216, doi:10.1029/2007JA012886, 2008.

Li, W., Thorne, R. M., Angelopoulos, V., Bonnell, J. W., McFadden, J. P., Carlson, C. W., LeContel, O., Roux, A., Glassmeier, K. H., and Auster, H. U.: Evaluation of whistler-mode chorus intensification on the nightside during an injection event observed on the THEMIS spacecraft, J. Geophys. Res., 114, A00C14, doi:10.1029/2008JA013554, 2009.

Li, W., Bortnik, J., Thorne, R. M., and Angelopoulos, V.: Global distribution of wave amplitudes and wave normal angles of chorus waves using THEMIS wave observations, J. Geophys. Res., 116, A12205, doi:10.1029/2011JA017035, 2011.

Lorentzen, K. R., Blake, J. B., Inan, U. S., and Bortnik, J.: Observations of relativistic electron microbursts in association with VLF chorus, J. Geophys. Res., 106, 6017-6027, doi:10.1029/2000JA003018, 2001.

Manninen, J., Kleimenova, N. G., Kozyreva, O. V., and Turunen, T.: Pc5 geomagnetic pulsations, pulsating particle precipitation, and VLF chorus: Case study on 24 November 2006, J. Geophys. Res., 115, A00F14, doi:10.1029/2009JA014837, 2010.

Oliven, M. N. and Gurnett, D. A.: Microburst phenomena: 3. An association between microbursts and VLF-chorus, J. Geophys. Res., 73, 2355-2362, 1968.

Santolik, O. and Gurnett, D.: Transverse dimensions of chorus in the source region, Geophys. Res. Lett., 30, 1031, doi:10.1029/2002GL016178, 2003.

Shukhtina, M. A. and Sergeev, V. A.: Modelling the drift of the real magnetosphere energetic particles in the vicinity of a geosyn- 
chronous orbit, Geomag. Aeron., 31, 775-780, 1991.

Smith, A. J., Horne, R. B., and Meredith, N. P.: Ground observations of chorus following geomagnetic storms, J. Geophys. Res., 109, A02205, doi:10.1029/2003JA010204, 2004.

Trakhtengerts, V. Yu.: Magnetosphere cyclotron maser: BWO generator regime, J. Geophys. Res., 100, 17205-17210, 1995.
Troitskaya, V. A. and Kleimenova, N. G.: Micropulsations and VLF-emissions during substorms, Planet. Space Sci., 20, 14991519, 1972.

Tsurutani, B. T. and Smith, E. J.: Postmidnight chorus: A substorm phenomenon, J. Geophys. Res., 79, 118-127, 1974.

Yearby, K. H. and Smith, A. J.: The polarization of whistlers received on the ground near $L=4$, J. Atmos. Terr. Phys., 56, 1499$1512,1994$. 